\title{
Pedagogía de la violencia y resistencias de las mujeres. El cuerpo como territorio en disputa
}

\author{
Pedagogy of violence and resistance of women. The body as \\ disputed territory
}

\author{
Mariana Alpízar Guerrero \\ Asociación Voces Violeta \\ San José, Costa Rica \\ marianaalpizarguerrero@gmail.com
}

\begin{abstract}
RESUMEN. El presente artículo es una propuesta teórica y conceptual para comprender los mecanismos en que opera la violencia como pedagogía que, no sólo reprime sino también moldea los cuerpos y les enseña cómo ser. Además, presenta una sistematización de las resistencias macropolíticas y micropolíticas que han utilizado históricamente las mujeres para lograr su sobrevivencia y mantener su autonomía. La perspectiva desde la cual se analizan estos conceptos y desde la cual se hace la historización, así como la aplicación de la teoría a ejemplos de la vida cotidiana es feminista y parte de la idea de que donde existe violencia siempre ha existido también la resistencia, siendo esta última una herramienta indispensable que han usado las mujeres para apalabrar su dolor, asumir su capacidad de agenciamiento e ir recuperando su cuerpo que ha sido un territorio histórico en disputa.
\end{abstract}

PALABRAS CLAVE. Violencia, resistencia, feminismo, mujeres, cuerpo

ABSTRACT. This article proposes a theoretical and conceptual approach to understanding the mechanisms in which violence works as a pedagogy that not only represses but molds the bodies, teaching them how to be.

Este es un artículo de acceso abierto publicado bajo los términos de la Licencia Creative Commons 4.0 Internacional Atribución-NoComercial-SinDerivadas. 
Also, it systematizes the macro and micropolitical resistances that women have used historically in order to survive and maintain their autonomy. The perspective from which these concepts are analyzed, the historization is made as well as the use of theory on examples of daily life is feminist, and builds up on the idea that when there has been violence, there has always been resistances. The latter is an essential tool that women have used to bespeak their stories of pain, assume their agency and progressively recover their bodies, which had been a disputed historical territory.

KEYWORDS. Violence, resistance, feminism, women, body

\section{INTRODUCCIÓN}

El presente artículo se basa en la tesis de graduación denominada Violencias y formas de resistencia. El caso de una mujer privada de libertad que cometió conyugicidio (Alpízar, 2019) ${ }^{1}$ y explora la violencia como una pedagogía que busca enseñar a los sujetos subalternos cuál es su lugar, tal como lo plantea Segato (2003). Asimismo, se profundiza en la violencia hacia las mujeres o hacia cuerpos feminizados ${ }^{2}$ como una lección que se repite y se actúa constantemente para dejar en claro que su espacio es el doméstico y que deben ser únicamente una extensión de los cuerpos masculinizados.

Por otra parte, se aborda la resistencia como acto que permite a los sujetos subalternos, en particular a los cuerpos feminizados, sobrevivir en sociedades patriarcales cuyo mensaje es la anulación, objetivación y muerte de estos cuerpos. En ese sentido, se parte de la idea foucaultiana de que donde existe el poder hay resistencia (Halperin, 2007), pues justamente la violencia, aunque es un mecanismo de control y disciplinamiento tiene grietas en sus alcances

1 La tesis se encuentra disponible en las bibliotecas de la Universidad de Costa Rica y puede consultarse la referencia al final de este texto.

2 En este artículo se usan ambas acepciones (mujer y cuerpo feminizado) para hacer referencia a los cuerpos que han sido moldeados de acuerdo a los mandatos de feminidad establecidos en las estructuras sociales patriarcales. La palabra mujeres, aunque pretende nombrar a la generalidad de estos cuerpos, no profundiza sobre las particularidades interseccionales y, por ende, en muchos casos ha sido usada para excluir corporalidades que no se adecuan a esa correspondencia esencialista, cisgenérica (y ficticia) entre lo biológico y lo social. Es por ello que en este artículo al usar el sustantivo "mujeres" no se pretende dar cuenta de la realidad de las mujeres desde todas sus diversidades. Por el contrario, se usan ambas acepciones con el objetivo de apuntar que tanto "mujeres" como "cuerpos feminizados" son categorías históricas, cambiantes y nunca por completo homogeneizantes. 
y las mujeres han resistido históricamente al anulamiento total. De allí que la resistencia, desde esta perspectiva, sea un concepto complejo - tal como el de violencia- que no es posible leer desde un lugar dicotómico y mutuamente excluyente, pues esta puede convertirse en violencia y viceversa.

Tanto la investigación de la tesis antes mencionada como el presente artículo parten del cuestionamiento a las dicotomías pasivo-activo, víctima-victimario que protagonizan el abordaje simplista de la violencia y abonan a la idea estereotipada de lo que debe ser una víctima y un victimario. Esto implica que, por ejemplo, si una persona subalterna se defiende, pasa a ser considerada violenta sin comprender las complejidades y matices que existen en el continuum violencia-resistencia.

Tal como se desarrollará en este artículo, en un abordaje dicotómico de la violencia se deslegitima la defensa y las resistencias, sobre todo si estas no logran su objetivo de suspender por completo la violencia. Y si existen respuestas ambiguas que los cuerpos feminizados llevan a cabo sin tener una claridad consciente de su objetivo, se considera que estas resistencias no son legítimas. Justamente ese abordaje de la violencia, asumido por la justicia punitiva, tiene consecuencias claras sobre la persecución a cierto tipo de cuerpos por encima de otros (Davis, 1981).

Por todo lo anterior, es necesario complejizar el abordaje de las violencias y el poder como algo que moldea y de lo cual no es posible "escapar". De manera que, para comprender los mecanismos de la violencia y de las resistencias es necesario adentrarnos no sólo en las formas macropolíticas de lucha sino en las expresiones micropolíticas de la resistencia.

A continuación, se iniciará con una propuesta para comprender teóricamente el concepto violencia pedagógica que ha sido trabajado fundamentalmente por Rita Segato $(2003,2006)$. Posteriormente, se aborda el tema de las resistencias de las mujeres tanto en el plano público como doméstico. Y, por último, se concluirá con algunas puntualizaciones sobre los conceptos mencionados buscando que estas puedan servir de base para trabajos posteriores en donde se haga un análisis aplicado del material teórico acá expuesto. 


\section{PEDAGOGÍA DE LA VIOLENCIA HACIA LAS MUJERES}

La violencia es una pedagogía aleccionadora que busca enseñarle constantemente a los cuerpos feminizados una serie de normas. Indica lo que las mujeres tienen prohibido, pero también lo que sí pueden hacer, es decir, controla, disciplina, castiga, pero también produce un modo de ser en el mundo. La violencia hacia las mujeres busca moldear su identidad. Ser mujer y vivir violencia se ha convertido en un binomio casi inseparable. En las sociedades capitalistas-patriarcales ser mujer es, entre otras cosas, ser objeto de violencia.

Ahora, la violencia hacia los cuerpos de las mujeres no llegó con el capitalismo, pues antes de la existencia de la industria, la moneda de intercambio entre hombres eran las mujeres. El intercambio homoerótico de las mujeres como mercancía, primer capital acumulable con valor de uso y valor de cambio (Irigaray, 1982), data incluso desde antes del genocidio colonial. Esto es lo que Lorena Cabnal llama patriarcado ancestral (2012), una cosmogonía que normalizaba la sumisión de los cuerpos feminizados antes de la llegada del colonialismo, momento en el cual se posibilita la intersección entre la base patriarcal que ya existía y las nuevas formas de violencia, tortura y esclavismo características de la imposición colonial.

A través del intercambio de mujeres se sustenta la economía masculinizada en la cual los sujetos que poseen el capital son los hombres. Desde una perspectiva psicoanalítica, esta economía se encuentra motivada por el tabú endogámico y homoerótico que se desea ocultar usando a las mujeres como mediadoras, como un espejo que reconozca su masculinidad heterosexual y oculte que en realidad no existe un otro. De esta manera, la unidad fálica es representada por un solo sujeto masculino que se relaciona consigo mismo económica y políticamente. Ese intercambio homoerótico no es en realidad una muestra de amor hacia el otro, sino que se trata de un mecanismo narcisista de autorreconocimiento.

Con el intercambio de mujeres y la economía masculinizada, el hombre demuestra su propia identidad. Una identidad que siempre está en tela de juicio, siempre es cuestionable, y por supuesto, aumenta en la medida que logre la acumulación de la mercancía (Irigaray, 1982). Al final, se trata de una lucha identitaria en un territorio en el que las mujeres son un bien preciado; no las mujeres en su particularidad sino como colectivo, dado que, por 
supuesto, las mujeres como individuas no son indispensables y, en el momento en que se muestren como amenaza o aspiren a convertirse en sujetas autónomas, pueden ser desechadas con la ley -también patriarcal一.

\section{LA VIOLACIÓN COMO ARMA DE CONTROL}

El principal mecanismo mediante el cual las mujeres son ubicadas en el lugar de subalternas es la violación, base del sistema patriarcal que moldea los cuerpos de las mujeres para enseñarles de forma sistemática cuál es su lugar (Segato, 2003), y no una práctica casual que sucede sin sentido lógico. Es decir, el cuerpo de las mujeres está en el estatuto de lo público y ha sido usado como forma de comunicación entre cuerpos masculinizados.

La violación, además de ser correctiva, es pedagógica y suele marcar las primeras experiencias sexuales de las mujeres. Despentes (2006) menciona de una forma cruda la realidad de la mayoría de las mujeres, diciendo que: "La violación a menudo es iniciática, esculpe en la carne para fabricar la mujer abierta" (p. 42). Las consecuencias psicosociales de la violación son múltiples, pero cuando suceden desde la temprana infancia lanzan el mensaje perverso de que sexualidad y abuso van de la mano, de modo que las sobrevivientes pasan años y algunas veces la vida entera intentando des-culpabilizarse y distanciarse del trauma.

Por su parte, la violación como mensaje coercitivo constituye un lenguaje de primacía masculina y demostración de poder en al menos dos vías: hacia las mujeres y hacia los pares. Segato (2003) enumera tres usos que tiene la violación como sistema pedagógico:

1. Como castigo o venganza contra una mujer genérica que salió de su lugar, esto es, de su posición subordinada y ostensiblemente tutelada en un sistema de estatus [...] El mero desplazamiento de la mujer hacia una posición no destinada a ella en la jerarquía del modelo tradicional pone en entredicho la posición del hombre en esa estructura, ya que el estatus es siempre un valor en un sistema de relaciones $[. .$.

2. Como agresión o afrenta contra otro hombre también genérico, cuyo poder es desafiado y su patrimonio usurpado mediante 
la apropiación de un cuerpo femenino o en un movimiento de restauración de un poder perdido para él [...]

3. Como una demostración de fuerza y virilidad ante una comunidad de pares, con el objetivo de garantizar o preservar un lugar entre ellos probándoles que uno tiene competencia sexual y fuerza física (p.p. 31-33).

En contextos geopolíticos de guerra, en el periodo de genocidio colonial, en la época del esclavismo en países como Estados Unidos o Sudáfrica o durante crisis económicas en la Industria, la violación ha jugado un papel fundamental, pues se usó no sólo como una forma de violencia cruenta y tortura hacia las mujeres - desde cada una de sus interseccionalidades como la raza, la etnia, la clase social, entre otras-, sino que se convirtió en un arma de sometimiento a los hombres que pertenecían a los grupos subalternos de los que también formaban parte las mujeres. Es decir, ellas, siendo una extensión de sus pares masculinos y formando parte del eslabón más bajo de la cadena no sólo eran violentadas física o psicológicamente, sino también sexualmente.

Incluso, cuando se piensa que la violación "vino" con la llegada de la Modernidad y que la explotación hacia las mujeres sucedió debido a procesos de apropiación imperialista contemporáneos, o que se trata de actos anómalos que suceden en momentos específicos, lo cierto es que la violación es una estrategia de coerción que se ha usado en diferentes momentos de la historia. Un mecanismo de control hacia las mujeres y hacia los otros hombres en el tanto es un arma efectiva para comunicar el mensaje de la supremacía e imponer la autoridad.

No se trata de un acto que usan solamente sujetos hegemónicos, sino que consiste en una pieza indispensable del engranaje patriarcal. La violación es "democrática", a ella tiene acceso el género masculino y sus consecuencias son vividas por las mujeres en diferentes niveles y durante toda la vida. Tanto Galindo, al respecto del patriarcado ancestral como Davis respecto a las particularidades de las mujeres negras ${ }^{3}$ durante el esclavismo en EE.UU. escriben:

3 Angela Davis habla de mujeres negras y no "afrodescendientes" apropiándose de un sustantivo que se ha usado de una forma negativa, pero que da cuenta del cuerpo como territorio historizado. En este artículo no se usa la palabra "afro- 
Las mujeres además de haber sido masivamente violadas, fueron también entregadas a los conquistadores en señal de alianza política, tal como ocurría antes de la conquista y prolongando más bien de cara al conquistador aquello que en el imperio inca era una práctica política altamente legítima, como era la de entregar y recoger a las mujeres niñas elegidas como parte del contrato de subordinación al inca por parte de las comunidades; como lo demuestra lrene Silverblatt en su libro Luna, Sol y brujas: género y clase en Los Andes prehispánico (Galindo, 2013, p. 100).

En tanto que mujeres, las esclavas eran esencialmente vulnerables a toda forma de coerción sexual. Si los castigos más violentos impuestos a los hombres consistían en flagelaciones y mutilaciones, las mujeres, además de flageladas y mutiladas, eran violadas (Davis, 1981, p. 16).

Tanto el patriarcado ancestral como el esclavismo con la intersección de género responden a contextos específicos y tienen particularidades que no serán profundizadas en este artículo; sin embargo, hay algo que tienen en común y es el uso de la violación como herramienta de sumisión. Angela Davis (1981) plantea que, en el contexto de la esclavitud, las mujeres no sólo debían llevar a cabo las mismas actividades que los hombres, cuestionando la idea del género femenino como débil presente en la cultura supremacista blanca, sino que, además eran víctimas de violaciones por parte de hombres blancos; actos que quedaban en la impunidad e incluso eran normalizados.

Cuando la violencia acontece en espacios donde es esperable - por ejemplo, en comunidades con altos niveles de desigualdadse naturaliza la violación; por lo tanto, el acceso a la justicia estatal es aún más difícil para las mujeres, ya que inicialmente los mecanismos normativos fueron construidos para proteger a cuerpos feminizados específicos de hombres específicos, es decir, para proteger la propiedad.

En Estados Unidos y en otros países capitalistas, las leyes contra la violación fueron originalmente formuladas para proteger a los

descendientes" porque en los debates actuales de los feminismos negros se ha visibilizado que su uso es incorrecto y puede ser racista pues alude al mito de que todas las personas negras provienen de África. Argumento utilizado para negarles su nacionalidad (tal como veremos más adelante esto efectivamente sucedió en Costa Rica). 
hombres de las clases altas frente a las agresiones que pudieran sufrir sus hijas y sus esposas. Habitualmente, los tribunales han prestado poca atención a lo que pudiera ocurrirles a las mujeres de la clase trabajadora y, por consiguiente, el número de hombres blancos procesados por la violencia sexual que han infligido a las mismas es extraordinariamente reducido. Aunque los violadores en raras ocasiones son llevados ante la justicia, los cargos de violación han sido imputados de manera indiscriminada a hombres negros, tanto culpables como inocentes. Así, 405 de los 455 hombres que fueron ejecutados entre 1930 y 1967 por una condena de violación eran negros (Davis, 1981, p. 175).

La justicia patriarcal ha incluido la violación como un delito históricamente pagado por hombres negros, indígenas, obreros, migrantes que, atentan contra mujeres blancas de clase media o de clase alta. Aun cuando efectivamente se trata de un acto al que todos los hombres tienen acceso, intersecciones como la clase social, la raza, la etnia o el estatus migratorio hacen que se juzgue sólo a ciertos hombres. Esto como si los hombres blancos, de clase media o alta, no violaran a sus pares o a mujeres subalternas.

Es así que, la justicia es patriarcal y capitalista, pues no sólo re-victimiza a las mujeres que intentan denunciar con procesos sumamente largos en donde siempre se cuestiona a la denunciante, sino que también interviene para mantener el orden jerárquico, clasista, racista y machista de la sociedad. La violencia busca lanzar un mensaje y es el de la domesticación de las mujeres como subalternas, lo cual se cruza, por supuesto, con su clase social, su raza, su etnia, su estatus migratorio, su edad o su orientación sexual para hacerles más vulnerables en la medida que vayan "sumando" características interseccionales de discriminación social.

No obstante, para entender cómo funciona la violencia en lo micropolítico se abordarán sus mecanismos en el plano el doméstico en donde suceden la mayoría de las violaciones y también la violencia física, psicológica y patrimonial. En las sociedades patriarcales, el que debería ser un espacio seguro es en realidad una zona de vulnerabilidad para los cuerpos feminizados desde edades tempranas. 


\section{MECANISMOS DE LA VIOLENCIA EN LOS ESPACIOS DOMÉSTICOS}

En el sistema capitalista-patriarcal la violencia hacia las mujeres es un continuum que se extiende desde la familia hasta el sistema educativo (Velázquez, 2003; Carcedo y Sagot, 2000). Dicha violencia tiene dos características centrales: la primera es que puede suceder en todos los espacios tanto públicos y la segunda es que cuando sucede en el plano intrafamiliar o de relaciones interpersonales, es cíclica y va en aumento, a menos que logre detenerse en algún punto de su ascenso.

El principal objetivo de la violencia hacia las mujeres es la des-subjetivación, es decir, la pérdida de la propia identidad y autonomía. De allí que, cuando sucede de forma sistemática, va dificultando cada vez más las herramientas de resistencia de las sobrevivientes y sus posibilidades de respuesta (Velázquez, 2003). El peligro constante, las amenazas y los mensajes contradictorios hacen que las mujeres que han vivido violencia sistemática se acerquen a la posición de pasividad que socialmente se espera de ellas.

No es cierto que las mujeres sean víctimas a priori o que sean violentadas porque son pasivas. La victimización es uno de los ejes de la violencia que busca arrebatarles, primero, simbólicamente y, luego, materialmente su capacidad de agenciamiento. Tanto los medios de comunicación como las instituciones de salud, de justicia y educativas, así como las personas cercanas a las mujeres sobrevivientes suelen aportar a la victimización de estas diciéndoles que ellas no hicieron nada para acabar con la situación de peligro.

La categoría de víctima asume que la persona que la porta no puede responder de ninguna forma a la violencia, si lo hace se convierte en una mala víctima perdiendo así la credibilidad ante un sistema de justicia binario, carente de matices y sin las herramientas para comprender la complejidad de la violencia.

En realidad, que una mujer resista de alguna o múltiples formas no la hace culpable de lo que vive, por el contrario, le da la posibilidad de sobrevivir. Si continua viva, es porque ha resistido y eso debe ser reconocido, no ocultado. Por su parte, si se considera que los victimarios son por completo activos, que tienen el monopolio de la fuerza y la autoridad total, también se pierde la capacidad de entender sus particularidades y modos sutiles de operar. 
Tal como explica Velázquez (2003) el moldeamiento que ejecuta la violencia sistemática en el cuerpo de las mujeres hace que vayan asumiendo, gradualmente, al menos tres sentimientos que se inscriben en su psique: el primero de ellos es el de desamparo, el segundo es la vivencia de peligro constante y el tercero sentirse diferente a los demás. La idea de que esta problemática sólo le sucede a ella, le hace sentir culpable de lo que le sucede y además alejada de sus redes de apoyo.

Debido a que la violencia sistemática es cíclica, siendo una de sus fases la llamada "luna de miel" y que la pedagogía del amor romántico enseña a las mujeres que el amor implica perdonar, se alienta la permanencia en vínculos que inician con violencia sutil y que, poco a poco, van ascendiendo hacia la violencia física. Si el vínculo no se acaba, garantizando la seguridad de la mujer sobreviviente con sus redes cercanas, la violencia sigue en aumento hasta poner en peligro su vida - por ello se habla de sobrevivencia-. Cuando las sociedades patriarcales alientan el perdón en la violencia "por amor", se entra en un escenario de muerte donde el feminicidio no sólo es posible, sino que pasa a formar parte de las amenazas constantes que reciben las mujeres y que en muchos casos finalmente se cumplen.

Ahora, tanto en el espacio doméstico como en el espacio público, el femicidio forma parte de un entramado mayor en la institucionalización de la violencia que justifica estos actos, culpabilizando a las víctimas. El cuerpo de las mujeres ha sido objetivado históricamente de diferentes formas, no sólo en la actualidad a través de los medios de comunicación, sino desde antes con la exclusión del sistema educativo, laboral y político, o aún más atrás con el intercambio de cuerpos de mujeres como moneda - actos que siguen sucediendo en la actualidad porque la historia no es lineal-, con la complicidad de los sistemas de organización política e, inclusive, con su participación directa.

Entonces tiene sentido que, en la actualidad, cuando sucede un femicidio las instituciones de justicia obstaculicen el proceso culpando a las mujeres porque, en realidad, forman parte de los actores que construyen el aparato de exclusión y objetivación de los cuerpos feminizados.

El femicidio no es un hecho que sucede en un momento particular sin tener conexión con lo social, sino que es parte del contexto 
donde el Estado también tiene un lugar; por ejemplo, cuando una mujer violentada intenta denunciar y es revictimizada, desalentando así su gesto autónomo (Carcedo y Sagot, 2000a; Carcedo y Sagot, 2000 b) o cuando se permite la exposición amarillista de los cuerpos muertos de las mujeres y se las señala como indignas. En la gran mayoría de los femicidios cometidos por la pareja, las mujeres han realizado denuncias que no son atendidas con inmediatez (Segato, 2006), o bien, deben dejar el proceso ya que este es revictimizante.

Parte del mecanismo perverso de justicia patriarcal es que haya tantos culpables que, al final nadie es culpable. Por ejemplo, el policía que cuestionó la ropa de la mujer denunciante, la amiga que no la sacó de su casa a rastras, la madre que no la obligó a irse, el médico que le creyó cuando le dijo que tenía moretones en el brazo porque se había caído, el jefe que la amonestó por bajar el rendimiento y no ahondó en las razones, el transeúnte que no intervino cuando vio a su pareja gritarle en la calle, etc. La culpa se va disgregando hasta que no queda nadie en la escena.

Tal como lo aborda a fondo Martín Baró, en su libro Acción e ideología (2012): "En sus experimentos sobre la irresponsabilidad moral de las personas frente a las necesidades de emergencia que presentan otros individuos, Latané y Darley $(1970,1976)$ encontraron que la presencia de otras personas estimulaba la pasividad de cada cual" (2012, p. 336). Es decir, la solidaridad muchas veces se ve inmovilizada por la corresponsabilidad social pues las personas que no causan directamente la violencia, no se sienten responsables de ella.

El femicidio es estructural y, a pesar de lo que cuentan los noticieros no es una falla en el sistema, más bien forma parte de la pedagogía de la violencia en donde se pone en evidencia que la objetivación de los cuerpos feminizados faculta también su muerte y exposición. Si las mujeres se atreven a andar solas por la calle, a trabajar, a dejar el espacio doméstico, a decir que no quieren tener relaciones sexuales, a dejar a su pareja que las violenta, entre muchas otras decisiones que las ubican como ser autónomo; reciben consecuencias que van desde la violencia verbal, en aumento hacia la violencia física y si esta no se detiene, persiste hasta la muerte.

De la misma forma, la categoría femicidio alude al profundo odio que tiene la sociedad patriarcal sobre los cuerpos feminizados, es decir, la misoginia que las termina matando por existir. Una 
de las características fundamentales de este crimen de odio es que suele realizarse con ensañamiento y violencia sexual. No basta el asesinato, sino que, además el cuerpo de las mujeres termina convirtiéndose en un mecanismo de comunicación patriarcal, pues, tal como lo investigó Rita Segato (2006) en Ciudad Juárez, en los cuerpos de las mujeres suelen escribirse mensajes con cuchillos, que intentan traspasar un mensaje a la colectividad. Así, los hombres que asesinan muestran su virilidad.

Por supuesto, como sucede con la violación, los cuerpos asesinados son los de mujeres pobres, migrantes, indígenas, negras, lesbianas, mujeres trans (Segato, 2006) y los hombres encarcelados son los hombres también subalternos, debido a que las leyes están hechas para proteger a ciertos sujetos y para garantizar el orden establecido, no para promover la equidad entre los géneros (Davis, 1981).

A pesar de ello, la denuncia sigue siendo un mecanismo necesario pues aun cuando la ley no tenga el objetivo de brindar justicia, es necesario visibilizar los crímenes de odio. Además, la ley es histórica, va cambiando a lo largo del tiempo porque el orden establecido tiene grietas por las cuales los cuerpos subalternos se han colado, han resistido y han ampliado la norma.

\section{LAS MUJERES-OBJETO EN LA LEY MODERNA}

En sociedades patriarcales es a través de figuras como el matrimonio y la institución de la familia que las mujeres pasan a ser legitimadas para tomar decisiones, las cuales deben ser avaladas, inicialmente, por el paterfamilias (Femenías, 2008). Existe, entonces, una dependencia matrimonial y maternal. Es por ello que, cuando se denuncian los femicidios el discurso suele aludir al parentesco con las mujeres para convencer al par masculino de que ellas merecen la vida, pues tienen valor si se las nombra hermanas, hijas, esposas, madres.

A partir de esta noción se asume que son los hombres los encargados de mantener a las mujeres bajo el margen de la ley, de manera tal que, si estas desobedecen, ellos podrían disciplinarlas. De hecho, en sus inicios, la legislación estadounidense normalizaba la violencia en el matrimonio, al punto que esta: 
No sólo no constituía delito ni tenía repercusiones civiles para el agresor, sino que era vista como una práctica generalmente aceptada, cuya base legal se remontaba a la legislación feudal inglesa y a las Leyes del Castigo romanas que reconocían el derecho absoluto del marido de disciplinar a la esposa (Carazo, 2007, 236).

Esto, también, sucedió en Costa Rica desde la legislación colonial hasta la liberal representada en el Código General de 1841. En ese código se autorizaba al marido a "reprender, amonestar y someter" (Rodríguez, 2006, p. 30) a su esposa a "moderados castigos domésticos" (p. 31).

En el caso del matrimonio y el derecho al divorcio en Costa Rica, así como el surgimiento de las leyes contra la violencia hacia las mujeres; inicialmente, hubo que eliminar el derecho de los esposos a reprender a la mujer; posteriormente, se le permite a las mujeres divorciarse, si prueban que están sufriendo maltratos - estas pruebas debían ser presentadas en la Iglesia y avaladas por un sacerdote-; luego, las mujeres acceden al derecho de divorcio civil (no eclesiástico) y; más adelante, se prohíbe la violencia en el matrimonio, las relaciones de pareja o dentro de la familia (Rodríguez, 2006).

Los avances políticos, legales y sociales no borran la memoria histórica. Si la ley desde sus inicios considera a los hombres como únicos sujetos de derecho y a las mujeres como objetos, la cultura seguirá promoviendo esta idea anclada en la memoria social que faculta a la violencia de género e, incluso, la promueve.

\section{PODER Y RESISTENCIA}

No es lo mismo violencia que resistencia. La violencia hacia las mujeres es sistemática, cíclica y va en aumento hasta poner en peligro la vida y tiene al menos dos objetivos: disciplinar y moldear los cuerpos feminizados enseñándoles cuál es su lugar y, comunicar a otros hombres la propia virilidad. Mientras que, la resistencia es una respuesta que puede ser puntual o sistemática, además puede ser organizada o individual y su objetivo es garantizar la sobrevivencia o agenciarse una vida digna.

Tanto la violencia como la resistencia tienen una conexión con los cuerpos que las ejercen y el contexto en el cual se realizan, así como el objetivo que tienen o el "para qué". De modo que no es lo 
mismo una mujer que asesina a su esposo en un contexto de violencia sistemática, enmarcado en una sociedad patriarcal, donde su vida está en peligro, que un hombre que asesina a su esposa para poseerla y que se justifica en instituciones como el amor romántico y una de sus expresiones: los celos, para cometer actos de anulación y objetivación de su pareja (Alpízar, 2019).

En libros como Historia de la sexualidad (1977) y Vigilar y Castigar (1975), Foucault moldea y perfecciona su conceptualización del poder incluyendo, no solo su veta disciplinaria, sino también la productiva (Días, 2006). Con esto marca una diferencia con la idea de que el poder únicamente oprime y da cabida a las resistencias como coextensivas al ejercicio de este. Para Foucault, en su etapa inicial, de los años setenta:

El poder, entonces, está en todas partes. La resistencia al poder se produce dentro del poder mismo, es parte de las relaciones de poder, de las relaciones estratégicas en que consiste el poder. Lo que escapa de las relaciones de poder-y algo siempre escapa, según Foucault-no está situado en un lugar fuera del alcance del poder, sino que representa su límite, su envés o contrapunto (como se citó en Halperin, 2007, p. 35).

De allí que no exista un afuera del poder y que las dicotomías sean más bien ilusorias, en el tanto que no existen únicamente víctimas y victimarios u opresores y oprimidos, sino que las tecnologías mediante las cuales el poder es ejercido también traspasan las respuestas que tienen los sujetos subalternos ante estas.

Decir que las mujeres que sufren violencia son víctimas pasivas no sólo es quitarles su capacidad de agenciamiento, sino que también contribuye a la perspectiva de la justicia patriarcal que estigmatiza y diferencia víctimas de victimarios, poniéndoles una serie de características esperadas que, de no cumplirse, cuestionan la veracidad de las denuncias. Es por ello que, tal como se trabajó en los apartados dedicados al tema de pedagogía de la violencia, hablar de sobrevivientes pone la atención en las herramientas de resistencia de las mujeres, quitándole a los llamados victimarios su poder totalitario sobre los cuerpos feminizados.

Si analizamos lo que tienen en común los extremos bueno-malo, oprimido-opresor, víctima-victimario, pasivo-activo, nos damos cuenta de que los buenos, los oprimidos, las víctimas y los pasivos tienen una serie de características asociadas a los roles patriarcales 
femeninos, tales como la debilidad, la dependencia y la vulnerabilidad. Mientras que los opresores, los victimarios y activos tienen características asociadas a lo masculino, tales como la fuerza, la independencia y el coraje, características que además son consideradas positivas.

Entonces, si el poder es más un continuum que un extremo y tiene una veta productiva y no únicamente represiva, las mujeres como subalternas ejercen, también, actos de resistencia cuando son violentadas en el sistema capitalista-patriarcal; actos que son invisibilizados socialmente con el fin de mantener el orden dicotómico establecido.

Así, tal como el poder es un continuum, también las resistencias, las cuales además son plurales y diversas. Pueden ser o no conscientes, suspender o no la violencia, pueden tomar múltiples formas; de modo que no es posible hacer una lectura dicotómica de estos conceptos pues se caería nuevamente en lo promovido por la justicia punitiva-patriarcal: construir un imaginario sobre la "buena víctima" y deslegitimar todo acto defensa en contextos de peligro.

A continuación, se profundizará más en el concepto de resistencia como actos que van también desde lo personal hasta lo colectivo.

\section{RESISTENCIAS COLECTIVAS E INTERSECCIONALIDAD}

Se dará inicio a esta discusión en torno a las resistencias macropolíticas de los cuerpos feminizados introduciendo el concepto "interseccionalidad", el cual es relativamente actual, pero sin él, se dificulta entender por qué la historia de los movimientos sociales de mujeres y los movimientos feministas no es lineal, no es homogénea y no es por completo inclusiva, pues además del género, hay otras categorías de exclusión social y jerarquización de los cuerpos que atraviesan a las personas que formaron y forman parte de los colectivos políticos organizados.

El concepto mismo de interseccionalidad fue acuñado en 1989 por la abogada afroestadounidense Kimberlé Crenshaw en el marco de la discusión de un caso concreto legal, con el objetivo de hacer evidente la invisibilidad jurídica de las múltiples dimensiones de opresión experimentadas por las trabajadoras negras de la 
compañía estadounidense General Motors. Con esta noción, Crenshaw esperaba destacar el hecho de que en Estados Unidos las mujeres negras estaban expuestas a violencias y discriminaciones por razones tanto de raza como de género y, sobre todo, buscaba crear categorías jurídicas concretas para enfrentar discriminaciones en múltiples y variados niveles (Viveros, 2016).

Es entonces cuando aparece la palabra interseccionalidad, para nombrar la diversidad de las personas subalternas, las categorías que atraviesan a los sujetos y en particular a las mujeres que no han sido oprimidas sólo en torno al género sino también a la raza, la clase social, la orientación sexual, la edad, entre otras intersecciones que les atraviesan también y que introducen conceptos que inicialmente no eran tomados en cuenta en los movimientos de mujeres y movimientos feministas: diferencia y diversidad. La interseccionalidad reconoce que una mujer privada de libertad, migrante nicaragüense, no tiene las mismas necesidades políticas que una mujer de clase alta habitante de la Gran Área Metropolitana.

Se considera que los movimientos feministas empezaron con la lucha por el derecho al voto, cuando en realidad las mujeres siempre han tenido un papel (y muchas veces este ha sido protagónico) en los espacios políticos organizados desde antes, muy a pesar de las prohibiciones patriarcales que intentaron ocultar su aporte.

Tal como lo trabaja Angela Davis (1981), las mujeres negras que formaron parte del movimiento abolicionista en Estados Unidos visibilizaron cómo la violencia que les traspasaba como esclavas tenía particularidades de género; por ejemplo, las violaciones que sufrían, los embarazos forzados y la doble carga que debían asumir cuando eran madres, cuidaban a sus hijos y trabajaban en los campos, pero además fueron enfáticas en señalar que aun con todas esas cargas, a las mujeres esclavas se les exigía tanto como los hombres, demanda que igualaban y en algunos casos superaban, es decir, no era verdad que las mujeres eran débiles. A pesar de esto tuvieron que luchar por tener palabra en el movimiento abolicionista y posteriormente en el movimiento sufragista blanco, pues justamente la intersección raza, género, clase social sumaba a las luchas que les pasaban por el cuerpo.

En 1851 en la convención de mujeres celebrada en Akron, Ohio, Sojourner Truth pronuncia su famoso discurso " ¿Acaso no soy una mujer?" respondiendo a un hombre que usaba el estereotipo de 
debilidad de las mujeres y la supuesta dependencia a los hombres como argumento en contra del sufragio femenino. Las palabras de Truth fueron además una visibilización del racismo en el movimiento sufragista que no tomaba en cuenta que las mujeres negras no habían dependido nunca de los hombres para mostrar su fuerza y que ellas, rompiendo con los estereotipos de género sobre la debilidad, eran también mujeres. Davis describe este histórico momento:

El líder de los provocadores había sostenido que era ridículo que las mujeres aspiraran a votar, dado que ni siquiera podían cruzar un charco o subir a un carruaje sin la ayuda de un hombre. Sojourner Truth señaló con una simplicidad demoledora que ella misma nunca había sido ayudada para pasar por encima de charcos embarrados o para subir a carruajes ¿Y acaso no soy una mujer? Su voz sonaba como el anuncio de un trueno, y dijo: Mírenme! Miren mi brazo y se remangó la manga para mostrar la tremenda fuerza muscular del mismo. ¡Yo he arado, he sembrado y he cosechado en los graneros sin que ningún hombre pudiera ganarme! ¿Y acaso no soy una mujer? Podía trabajar tanto como un hombre, y comer tanto como él cuando tenía la comida ¡Y, también, soportar el látigo! ¿Y acaso no soy una mujer? He dado a luz a trece niños y he visto vender a la mayoría de ellos a la esclavitud iy cuando grité, con mi dolor de madre, nadie sino Jesús pudo escucharme! ¿Y acaso no soy una mujer? Siendo la única mujer negra asistente a la convención de Akron, Sojourner Truth había hecho lo que ninguna de sus tímidas hermanas blancas era capaz de hacer" (Davis, 1981, p. 69).

Aunque en EE.UU. la lucha por los derechos de las mujeres sucedía paralelo a la lucha abolicionista y las luchas laborales, dentro de los movimientos sufragistas se mantenía el racismo y el clasismo, pues algunas de sus lideresas ponían sus derechos por encima de los derechos de hombres negros y en muchos casos argumentaban una superioridad de las mujeres burguesas sobre estos (Davis, 1981).

El discurso del movimiento feminista blanco en EE.UU., y en otras partes del mundo, fue en torno a garantizar la participación en el espacio público-político de las mujeres, cuestionando la naturalización del espacio doméstico en que se las había confinado. Sin embargo, las mujeres obreras y las mujeres negras hace décadas habitaban el espacio público, trabajaban, eran explotadas y debían mantener dobles o triples jornadas. Si bien la lucha por los derechos políticos de las mujeres era fundamental, en sus inicios dejaba 
de lado las demandas de las mujeres negras y obreras. Valga decir que, además, las mujeres obreras más explotadas eran las migrantes, pues los patronos las contrataban para pagarles menos, por más horas de trabajo.

En Costa Rica, por su parte, el camino para lograr el sufragio femenino fue largo y tuvo también disputas relacionadas con la importancia de incluir las demandas de las mujeres obreras y mujeres negras, así como a mujeres indígenas. Aunque la historia suele centrarse en las luchas de mujeres blancas burguesas, es fundamental que la investigación intente ahondar en una lucha que tiene características interseccionales. No es gratuito que se haya intentado invisibilizar el aporte de mujeres obreras, indígenas o negras a la historia del país.

En el movimiento sufragista costarricense, tal como sucedió en Europa y EE.UU., una de las estrategias para lograr el avance de los derechos políticos fue la alianza con hombres blancos y la higienización del discurso que colocaba a las mujeres como un género inofensivo, merecedor del voto en el tanto ellas garantizaban el sostenimiento a los valores familiares y la "limpieza" de una sociedad corrompida por los vicios y la violencia. Es decir, siempre y cuando las mujeres siguieran operando como reproductoras del orden establecido y no dejaran sus responsabilidades domésticas, podían participar en labores de la vida política. Tal como lo muestra la investigación realizada por Eugenia Rodríguez, al mostrar los discursos de las mujeres sufragistas en Costa Rica:

Un ejemplo de la concordancia con la óptica liberal es el discurso de Sara Casal, una de las principales líderes de la Liga Feminista, la cual tendría a enfatizar la importancia de moralizar e higienizar a los sectores populares y la necesidad de armonizar las relaciones sociales a partir del hogar. En este proceso las mujeres, las maestras y las madres estaban destinadas, por su naturaleza moral, a jugar un papel crucial en la erradicación de una wserie de males sociales que afectaban a sus hijos y en la promoción de la paz en el hogar y en la sociedad (Rodríguez, 2006, p. 78).

Uno de los mayores antecesores de la lucha sufragista, que inicialmente fue liderada por mujeres que habían hecho sus estudios superiores en Europa, fue el derecho a la educación (Arce, 2012). En una sociedad liberal que defendía el papel civilizador y colonialista de la educación, se argumentaba que las mujeres debían educarse 
para ejercer labores domésticas; sin embargo, fue esta la primera puerta que se abrió para conseguir derechos políticos.

El Colegio Superior de Señoritas fue un semillero donde se formaron una serie de mujeres destacadas. Por ejemplo, en 1921 se graduó de maestra normal Emilia Prieto Tugores, quién dedicó veinte años de su vida a la docencia. En el año de 1935 organizó el primer desfile de carretas que se realizó en el país. En el año de 1936 fue fundadora de la Liga Antifascista [...] Ángela Acuña Braun (1888-1983), fue la primera mujer en graduarse en Derecho en 1925 y es considerada la pionera del movimiento feminista en Costa Rica. En 1923 funda la Liga Feminista, primer grupo organizado de mujeres para la obtención del sufragio femenino en alianza con las profesoras y estudiantes del Colegio de Señoritas (Arce, 2012, p. 15).

Por su parte, Carmen Lyra, quien fue perseguida por formar parte del Partido Comunista, inicialmente consideraba que la lucha sufragista estaba dejando de lado las necesidades de las mujeres obreras. Cuando en 1949 se ilegaliza en Costa Rica el Partido Comunista, se crean estrategias internas para seguir con las diferentes luchas, como la creación de grupos específicos dirigidos a mujeres. La Alianza de Mujeres se enfocó en promover el liderazgo político en las organizaciones de base, es decir, en las comunidades, donde las mujeres ya tenían, y siguen teniendo, una importante labor (Arce, 2012).

Finalmente, el 20 de junio 1949 se aprueba constitucionalmente el voto femenino (Arce, 2012), pero el camino tuvo múltiples obstáculos por parte no sólo de instituciones políticas, sino familiares y eclesiásticas patriarcales, quienes consideraban que el voto femenino era un retroceso en el desarrollo del país. Hubo una gran división de sectores y quienes defendían el sufragio empezaron a usar un discurso en el que se ubicaba a las mujeres como merecedoras de este derecho. Se decía en periódicos, en asambleas, en reuniones, en campañas, que las mujeres debían votar en el tanto eran ciudadanas que aportaban al crecimiento del país, desde una perspectiva liberal.

Rodríguez (2006) plantea que el Partido Reformista, por ejemplo, tenía como puntos de agenda para las Mujeres Reformistas los siguientes: La eliminación de la Fábrica Nacional de Licores, colocar fuera de la ciudad moderna a quienes llamaban prostitutas, y fundar un asilo de cuna para las madres pobres que trabajaban. Es 
decir, se mantenía el lugar maternal y moral de las mujeres que ya habían ejecutado públicamente desde espacios como las iglesias. A continuación, se resume el discurso liberal civilizatorio de la mujer como merecedora del voto usado en la época, en palabras de Rosa Casals, citada en Rodríguez (2006):

La institución de la mujer es un factor esencial que deben tener en cuenta los que anhelan renovar la sociedad actual y aspiran a civilizar a los pueblos. La mujer instruida, educada convenientemente, ya comprendería lo bueno y lo malo... y estaría bien preparada para hacer de sus hijos hombres honrados e inteligentes, libres, buenos (p. 87).

En este extracto no sólo existe una naturalización del papel de las mujeres como madres en el plano doméstico, sino también en el espacio político y público. Además, el discurso está dirigido a legitimar a las mujeres que han recibido educación formal, asumiendo que son ellas las merecedoras del voto.

Como se mostraba al inicio, si la educación ya tenía como objetivo el disciplinamiento doméstico de las mujeres, es decir, prepararlas para el matrimonio, con el voto se buscaba institucionalizar una feminidad que no fuera amenazante al orden establecido. Por supuesto que, por ejemplo, mujeres sin educación formal, de la clase trabajadora, mujeres indígenas y mujeres negras no solo fueron excluidas del discurso sufragista, sino que, muchas de ellas pudieron acceder a ese derecho mucho después que las mujeres blancas, de clase media o alta. A continuación, se muestran dos citas donde se habla inicialmente de la población negra y posteriormente de las personas indígenas:

Las personas afrodescendientes, nacidas en el territorio costarricense fueron consideradas, en la primera mitad del siglo XX como extranjeras. Previo a la adquisición de la ciudadanía debieron transitar por el proceso de naturalización, lo cual les dio el acceso a la cédula y al ejercicio de la ciudadanía nacional. Miles de mujeres y hombres afrocaribeños nacidos antes de 1949, permanecían inscritos con estatus de extranjeros (Arce, 2012, p. 27).

Es hasta 1949 que las mujeres tuvieron el derecho al voto, como resultado de los movimientos establecidos con tales propósitos. Aún así, cuando este derecho ciudadano se extiende por igual a todas las personas adultas costarricenses, hubo un segmento de la población 
que siendo originaria en el país no obtuvo la nacionalidad hasta el año 1990 y, por lo tanto, no pudo elegir ni ser electa las poblaciones indígenas no pudieron votar hasta finales del siglo XX (Arce, 2012, p. 28).

Es fundamental reconocer que el derecho al voto fue uno de los mayores avances que han tenido las mujeres gracias a la resistencia organizada, sin embargo, también dentro de los movimientos sociales había racismo y clasismo. Este es un ejemplo de que no hay un afuera del poder y tanto las violencias como las resistencias son complejas.

Aun cuando, por razones de espacio no sea posible trabajar a profundidad la segunda ola del feminismo y particularmente el feminismo de la diferencia, así como abordar el feminismo post-estructuralista, sí sería importante mencionar algunos de los hechos más significativos que marcaron estas luchas y dan cuenta de la necesidad de ampliación de interseccionalidades, incluidas en lo que homogéneamente se nombraba como mujeres.

Es, además, necesario este pasaje por lo colectivo para comprender cómo afectan las luchas sociales a las herramientas de resistencia cotidiana que usan las mujeres en los espacios micro políticos, es decir, en sus casas, en las calles, en sus trabajos, etc. Tanto el feminismo de la diferencia, como el posestructuralista, incluso el feminismo de la igualdad - como vimos anteriormente- amplían y, en algunos casos, cuestionan el concepto mujeres y las luchas sociales son espejos que también afectan y se ven afectados por lo que sucede en los espacios domésticos o privados.

La famosa frase "lo personal es político" dicha por Kate Millet (1969), trae al espacio de lo político algo que anteriormente era colocado a conveniencia en lo privado, el cuestionamiento a la violencia doméstica y la puesta en discusión de los derechos sexuales y reproductivos. Lo personal como algo político reivindica nuevas demandas para las mujeres, abriendo las puertas de la casa, lugar de poder donde se ejercen las tareas de disciplinamiento genérico familiar. Lo sexual, que tenía el estatuto de lo prohibido o lo que no se podía hablar, empieza a ser un tema de discusión política.

Monique Wittig (1992), teórica lesbofeminista, planteó que la heteronorma define una manera de ser mujer que pasa por el ejercicio de la maternidad y en ese caso las lesbianas, que no podían adoptar ni tener hijos e hijas no eran consideradas mujeres. Wittig 
(1992) señaló que la heterosexualidad es un mandato que establece roles de acuerdo al sexo y ha colocado en el imaginario social la supuesta existencia de un continuum lineal entre las categorías género-sexo-orientación sexual. Así una hembra humana es mujer y debe orientar su deseo hacia los hombres, por ejemplo.

Tal como lo trabaja Butler (2007), Wittig pone en el lenguaje un gran peso en la configuración material de los sujetos, en el moldeamiento de los cuerpos de una forma genérica. El lenguaje es herramienta de violencia, pero también es forma de resistencia en el tanto nombrarse; por ejemplo, lesbiana cuestiona la linealidad sexo-género-orientación sexual y mina el sistema heteronormado que nos dice a los hombres y las mujeres cómo debemos ser, dejando en evidencia que esa ley preestablecida es en realidad una fantasía y que no existe sólo la heterosexualidad que faculta a la maternidad y paternidad como algo únicamente biológico.

Esta discusión introduce lo que actualmente se denomina Teoría Queer, la cual pone, tal como lo nombra Butler, al género en disputa (2007) a través de preguntas no sólo en torno a las identidades o a la orientación sexual sino también al sexo mismo o lo biológico que era algo incuestionable. Las personas intersexuales que portan en su cuerpo diversidades anatómicas, cromosómicas y hormonales, amplían el espectro binario masculino-femenino, su existencia subvierte la dicotomía corporal que ya había sido asumida por el discurso científico y médico. La teoría queer retoma el debate sobre el cuerpo para visibilizar que la diversidad también existe en lo biológico. Lo "natural" es diverso en sí mismo.

Debido al discurso médico que sigue siendo binario, las personas intersex son mutiladas al nacer y se les asigna un sexo sin que intervenga su opinión y en muchos casos ni siquiera se les consulta al padre y la madre. A pesar de que existe una evidente vulneración a sus derechos humanos, las luchas de las personas intersex no siempre fueron parte de los movimientos feministas. Fue hasta hace poco tiempo, en los años ochenta particularmente, cuando se empezó a movilizar la lucha por los consentimientos informados para las operaciones a personas intersex, cuando Cheryl fundó la famosa Sociedad Intersexual de Norteamérica, más conocida por las siglas ISNA (Hernández, 2009).

Justamente, también los transfeminismos denuncian cómo algunos movimientos feministas asumen que las luchas y demandas 
deben ir en torno a las problemáticas cis-genéricas, excluyendo las particularidades de las mujeres trans y en muchos casos excluyéndolas del colectivo mujeres. Existen algunos feminismos que siguen dotando a lo biológico de un estatuto de verdad.

Algunos de los primeros trabajos que surgieron desde una perspectiva feminista en torno a la cuestión trans estuvieron marcados por una actitud hostil. Un ejemplo es la obra publicada en 1979 por la feminista Janice Raymond titulada The transsexual empire: the making of the she-male, en la cual se realiza una crítica a la transexualidad como fenómeno médico. Raymond parte de la idea de que el sexo es un dato que existe previamente a las maquinaciones de la cultura. Por tanto, la pertenencia de un individuo a la categoría de mujer es determinada en primer lugar por los cromosomas y en segundo, por su historia de experiencia individual de ser asignado a un rol de sexo. Partiendo de lo anterior, esta pensadora feminista sostiene que las mujeres trans son en realidad hombres y que su experiencia es incapaz de reflejar la historia de los daños causados a las mujeres por la opresión de los roles sexuales (Nolasco, 2016, p. 3).

Las mujeres, como decía Beauvoir, no nacen, llegan a serlo, a través de la cultura que se imparte desde el seno familiar. Se usa la justificación de lo "natural" para normalizar el lugar de subalternidad de las mujeres. Dentro de los movimientos de resistencia también ha sido necesario cuestionar las normas que se han asumido en torno a la homogeneización y esencialismo del sujeto de las luchas feministas, las mujeres. La interseccionalidad en las luchas es fundamental para reconocer la diversidad y la particularidad en las necesidades de los colectivos sociales, sin asumir que las necesidades de algunas, son las de todas.

Es por ello que, se hacen fundamentales dos mecanismos de resistencia que han sido invisibilizados en la estructura patriarcal, por su peligrosidad y potencial subversivo: uno, dejar de competir entre mujeres, es decir, dejar de actuar como mercancía y construir un lenguaje propio, para así poder devenir sujetas y no objetos, dos, legitimar, visibilizar, reconocer todos los actos de resistencia que han tenido las mujeres para sobrevivir y existir dignamente, porque esas han sido las herramientas de subjetivación y autonomía subversivas que cuestionan el lugar de invisibilidad y muerte en que nos han colocado. Concretamente reconocer que, si no fuera 
por nuestras resistencias, no podríamos sobrevivir.

Con respecto al primer punto, se hace necesario construir un lenguaje de colaboración, diferente al discurso de la competencia que obstaculiza la comunicación entre mujeres. Para devenir sujetas es necesario inicialmente retomar su propia voz, no desde los cánones del capitalismo patriarcal, sino desde un lugar particular.

El tema de la recuperación de la voz ha sido abordado por Luce Irigaray (1982), quien hace referencia a la necesidad de construir un lenguaje plural, pues en las sociedades patriarcales existe solo un sujeto capaz de enunciar y ser enunciado y es masculinizado, desde la unidad falocéntrica en la cual la mujer sería objeto de intercambio y no sujeta de palabra. En esta línea Spivak, en su texto "¿Puede hablar el sujeto subalterno?" (2003), hace una crítica al sector académico que habla de las personas subalternas sin incluirles realmente en la discusión, es decir, desde un lugar jerarquizado, de allí que la producción epistemológica desde sí, desde la construcción de un lenguaje plural, sea importante y también un acto de resistencia.

El segundo punto es un llamado a reconocer que el camino para devenir sujetas implica dejar de jerarquizar unas resistencias por encima de otras. En espacios institucionales, por ejemplo, de salud mental, o las instituciones de justicia y en relaciones interpersonales directas con mujeres sobrevivientes de violencia es necesario legitimar sus resistencias, apoyarlas para que ellas las puedan nombrar y asuman así, en red, su propia autonomía. Ambos puntos llevan la mirada hacia escenarios donde generalmente no se enfocan los esfuerzos por construir sociedades más equitativas, pues estos se han centrado en repetir el discurso masculinizado de competencia, de priorización de luchas, de priorización de ciertas tácticas y estrategias de resistencia como las "mejores" para lograr la consecución de derechos.

Chantal Mouffé (2014) plantea la importancia de asumir el antagonismo como algo que forma parte de los movimientos sociales y de la vida en general. La disidencia, la falta de acuerdo, la discusión y el diálogo son elementos que pluralizan lo que entendemos por democracia, mientras que la censura, la jerarquización de las luchas y la consecuente división entre resistencias legítimas e ilegítimas crea fisuras excluyendo a ciertos cuerpos y jerarquizando experiencias. 
Generalmente cuando se habla de resistencia se piensa en actos organizados y públicos, pero en la casa también se libran batallas cada día por la sobrevivencia. A continuación, se abordan las micropolíticas de la resistencia en el plano de lo doméstico.

\section{RESISTENCIAS COTIDIANAS EN EL ESPACIO MÁS INSEGURO PARA LAS MUJERES: EL HOGAR}

Las cifras en América Latina muestran que el espacio doméstico no es una zona segura "en Chile el $60 \%$ de las mujeres que viven en pareja sufre algún tipo de violencia doméstica, el 70\% en México y en Perú. Mientras que en Nicaragua el 32,8\% de las mujeres entre 14 y 19 años son víctimas de violencia física severa" (Velázquez, 2003, p. 32). Además, entre las consecuencias psicosociales que tiene la violencia se contabiliza que "la victimización de género es responsable de 1 de cada 5 días de vida saludable perdidos por mujeres en edad reproductiva (entre 15 y 44 años de edad). Es decir, casi un año de vida perdido por cada 5 de vida saludable" (p. 31).

La denuncia es una opción que suele revictimizar a las mujeres obligándolas a ejercer el lugar de "buena víctima", de modo que si no presentan pruebas de su completa pasividad y de que el acto de violencia puso en peligro su vida, su palabra deja de ser legítima, por lo que, la justicia punitiva las termina culpabilizando. Esto a pesar de que la violencia tiene un ciclo que es difícil de detectar porque inicia de formas muy sutiles y a las mujeres se les enseña a ignorar su intuición y a "dejar pasar".

Si fuera real el mito de que la violencia únicamente se ve expresada en ataques físicos, donde el perpetrador usa toda su fuerza y pone, también desde el inicio, en peligro la vida de la víctima; tendría más sentido el método de justicia actual. Sin embargo, la violencia doméstica es cíclica y sistemática, va quitándole a las mujeres las herramientas para responder. Por eso, tampoco es sensato esperar que ante la primera muestra de violencia sutil y cuando el mensaje de amor romántico es el perdón, así como la pasividad femenina, las mujeres dejen a sus parejas, les denuncien, o incluso que les confronten directamente.

Una de las formas de resistencia que han ayudado a las mujeres a sobrevivir es la negociación en contextos de peligro. Velázquez 
(2003) cuenta cómo una mujer, a quien nombra Marta, al darse cuenta que estaba a punto de ser violada, invitó al perpetrador a tomar café, logrando entonces distraerlo. Desde la justicia patriarcal se pensaría que ella se ponía en un lugar vulnerable y, por tanto, de consentimiento; sin embargo, este tipo de estrategias son las que permiten a las mujeres librarse de la violencia, al menos momentáneamente.

La experiencia con mujeres agredidas nos ha demostrado que ellas disponían, además de estos mecanismos defensivos, de otros recursos que utilizaron antes o durante el ataque. Persuasión, chantaje emocional, seducción, promesas, son algunas de las maneras de aferrarse a la idea de vida y sentir que se puede tener controlado el peligro. Estos recursos constituyen medios para lograr reaseguro y autovaloración (Velázquez, 2003, p. 63).

Es fundamental reconocer estos actos de resistencia que no buscan únicamente salir de esa situación, sino mantener su capacidad de agenciamiento y por lo tanto su propia identidad como sujetas, quebrar la omnipotencia del otro y desmitificar su lugar de completo poder sobre sus cuerpos. Tal como plantea Lorena Cabnal, recuperar el territorio cuerpo.

Recuperar y defender el cuerpo, también implica de manera consciente provocar el desmontaje de los pactos masculinos con los que convivimos, implica cuestionar y provocar el desmontaje de nuestros cuerpos femeninos para su libertad. Es un planteamiento que nos invita a recuperar el cuerpo para promover la vida en dignidad desde un lugar en concreto, a reconocer su resistencia histórica y su dimensionalidad de potencia transgresora, transformadora, y creadora. Parte de la recuperación de la memoria cósmica corporal de las ancestras, para ir tejiendo su propia historia desde su memoria corporal particular, y como decide relacionarse con las otras y otros. Siente, piensa, decide y acciona a partir de internalizar nuevas prácticas como el autoerotismo, el disfrute de la dimensionalidad sexual en libertad, el placer, el arte, la palabra, el ocio y descanso, la sanación interior, la rebeldía, la alegría... Es una propuesta feminista que integra la lucha histórica y cotidiana de nuestros pueblos para la recuperación y defensa del territorio tierra, como una garantía de espacio concreto territorial, donde se manifiesta la vida de los cuerpos (2010, p. 22-23).

El cuerpo de las mujeres ha sido un territorio que ha estado his- 
tóricamente en disputa, de modo que el inicio de las resistencias empieza por lo personal, por reapropiarse de ese lugar y quitarle su estatuto de propiedad del otro o de objeto fetichizado para complacer. El mensaje es que sin esa unidad masculinizada de la que las mujeres sólo son parte, no es posible existir. El amor romántico y la competencia entre mujeres, hace que el enfoque sea hacia los sujetos hegemónicos e impide que las mujeres construyan su propio lenguaje, de modo que el primer territorio a recuperar es nuestro cuerpo, cuerpo individual y cuerpo colectivo.

\section{CONCLUSIONES}

Este texto busca ser una introducción a las generalidades de la violencia y a los mecanismos de resistencia, es por ello que a continuación se muestran algunos puntos que resumen la propuesta teórica-conceptual que se ha trabajado en el presente artículo, buscando que la sistematización no sea el final de las discusiones, sino el inicio de estas.

En ese sentido, la violencia es una pedagogía que no sólo reprime ciertos actos, sino que también moldea los cuerpos dentro de un sistema desigual en términos de género, clase social, etnia, raza, edad, entre otras categorías que, desde la lógica patriarcal, justifican la exclusión.

Asimismo, históricamente la violencia hacia las mujeres ha buscado su objetivación usando mecanismos como la violación o el femicidio que no sólo se usan como castigo, sino que han llegado a ser un peligro inminente al que se enfrentan las mujeres por el hecho de serlo. Además, estos mecanismos funcionan como un lenguaje perverso que usan tanto los hombres que los ejercen directamente como aquellos a quienes va dirigido el mensaje, para subrayar que los cuerpos de las mujeres son objetos que pueden ser usados, intercambiados y desechados.

También se tiene que, la dicotomía víctimas-victimarios contribuye a la idea estereotipada de que las mujeres son pasivas y que los hombres tienen el poder total. Hablar de las formas de resistencia que usan las mujeres para sobrevivir y llamarles, asimismo, sobrevivientes, nombra la capacidad de agenciamiento de las mujeres apoyando su proceso hacia la reconstrucción de su autonomía.

De este modo, la violencia doméstica es sistemática y cíclica, an- 
clada a la idea de perdón del amor romántico y se encuentra inserta en un sistema desigual en donde la justicia también es patriarcal. Es por ello que se deslegitiman las denuncias de las mujeres que no caben en el estereotipo de víctima lanzándolas a buscar otros medios para defenderse.

Además, los movimientos sociales no son homogéneos y desprovistos de contradicciones. Los movimientos feministas de resistencia organizada también han reproducido racismos, colonialismos, clasismos, esencialismos e incluso machismos e internamente han sido cuestionados por mujeres, también feministas que han luchado por hacer de los movimientos un espacio interseccional. Visibilizar y nombrar las contradicciones también ha sido parte destacable de los movimientos feministas subalternos, que, al mirar hacia adentro han logrado ir abriendo la conceptualización de la categoría mujeres fuera del esencialismo normativo.

Y, por último, toda resistencia — sea colectiva y organizada o individual y micropolítica-mueve de alguna forma el orden establecido pues cuestiona la idea de las mujeres como objeto, ubicándose ellas como sujetas con capacidad de agenciamiento. Desde esta perspectiva, toda resistencia es legítima.

\section{BIBLIOGRAFÍA}

Alpízar, M. (2019). Violencias y formas de resistencia: El caso de una mujer privada de libertad que cometió conyugicidio (Tesis de licenciatura). Universidad de Costa Rica, San José, Costa Rica.

Amorós, C. (1991). Hacia una crítica de la razón patriarcal. Anthropos.

Arce, P. (2012). Para elegir y ser electas. Una reconstrucción histórica. INAMU.

Baró, M. (2012). Acción e ideología. Psicología Social desde Centroamérica. UCA Editores, San Salvador.

Butler, J. (2014). El género en disputa: El feminismo y la subversión de la identidad. Paidós.

Cabnal, L. (2010). Acercamiento a la construcción de la propuesta de pensamiento epistémico de las mujeres indígenas feministas comunitarias de Abya Yala. ACSUR. https://porunavidavivible.files.wordpress.com/2012/09/feminismos-comunitario-lorena-cabnal.pdf

Carazo, A. (2007). Aspectos generales sobre el tratamiento jurídico y social de la víctima de violencia doméstica inmigrante en los Estados Unidos. EGUZKILORE, (21), 235-256. 
Carcedo, A. y Sagot, M. (2000a). Feminicio en Costa Rica de 1990-1999. INAMU.

Carcedo, A. y Sagot, M. (2000b). Ruta crítica de las mujeres afectadas por la violencia intrafamiliar en América Latina. Zeta Servicios Gráficos.

Davis, A. (1981). Mujeres, raza y clase. Cofás.

Despentes, V. (2006). Teoría King Kong. Editorial Melusina.

Días, R. (2006). Poder y resistencia en Michel Foucault. Tábula Rasa, (4), 103-122.

Femenías, M. L. (2008). Violencia contra las mujeres: urdimbres que marcan la trama. Edulp.

Foucault, M. (1975). Vigilar y castigar. Nacimiento de la prisión. Siglo Veintiuno.

Foucault, M. (1977). Historia de la sexualidad. Siglo Veintiuno.

Halperin, D. (2007). San Foucault. Para una hagiografía gay. Cuadernos de Litoral.

Hernández, V. (2009). Intersexualidad y prácticas científicas: ¿ciencia o ficción? Revista de Investigaciones Politicas y Sociológicas, 8 (1), 89-102.

Irigaray, L. (1982). Ese sexo que no es uno. Saltés.

Millet, K. (1969). Politica Sexual. Recuperado de https://revistaemancipa. org/wp-content/uploads/2017/09/Kate-Millett-Politica-sexual.pdf

Mouffe, C. (2014). Agonística. Pensar el mundo políticamente. Fondo de Cultura Económica.

Nolasco, P. (2016, 24-25 de noviembre). Identidad(es) transgénero: una reconstrucción histórica desde una perspectiva feminista [ponencia]. 1er Coloquio interinstitucional de programas de doctorado en ciencias sociales y humanas, Universidad de Colima, México. www.academia. edu

Pateman, C. (1988). El contrato sexual. Barcelona, Anthropos.

Rodríguez, E. (2006). Divorcio y violencia de pareja en Costa Rica (18001950). San José, EUNA.

Segato, R. (2003). Contra pedagogías de la crueldad. Prometeo libros.

Segato, R. (2006). La escritura en el cuerpo de las mujeres asesinadas en Ciudad Juárez Territorio, soberanía y crímenes de segundo estado. Tinta Limón.

Spivak, G. (2010). ¿Puede hablar el sujeto subalterno? Memoria Académica, $3(6), 175-235$.

Velázquez, S. (2003). Violencias cotidianas, violencia de género. Escuchar, comprender y ayudar. Paidós. 
ANUARIO DEL CENTRO DE INVESTIGACIÓN Y ESTUDIOS POLÍTICOS

Wittig, M. (1992). El pensamiento heterosexual y otros ensayos. Egales.

MARIANA ALPÍZAR GUERRERO es costarricense. Licenciada en Psicología por la Universidad de Costa Rica. Psicóloga e investigadora feminista. Labora en la Asociación Voces Violeta. 